\title{
An Investigation of the Problems Jordanian EFL Learners Encounter in Presupposition Triggered by Certain Factive Verbs
}

\author{
Hamzah Saleh Ghammaz \\ College of Islamic and Arabic Studies, 96749 Dubai, UAE \\ E-mail: ibtaa@hotmail.com
}

Received: 20-04- 2015

Published: 01-11- 2015
Accepted: 25-07- 2015

doi:10.7575/aiac.ijalel.v.4n.6p.172
Advance Access Published: August 2015

URL: http://dx.doi.org/10.7575/aiac.ijalel.v.4n.6p.172

\begin{abstract}
This study aimed at investigating the problems that Jordanian EFL learners encounter in presupposition triggered by certain factive verbs. Specifically, it sought to find out whether there is a relationship between the subjects' proficiency level in English and their correct recognition of presupposition triggered by certain factive verbs. It also aims at identifying which factive verbs are much more difficult than others in terms of the presupposed meaning. The subjects of the study were 70 adult learners of English at the University of Jordan. They belong to two different proficiency levels: Intermediate and Advanced. A special test was prepared to elicit the data needed for investigation. The test required the subjects to circle the best choice that presupposes a given sentence. The results showed that the Advanced Group outperformed the Intermediate Group on all the target factive verbs, and the factive verb " be aware of " proved to be the most difficult one followed by "forget". The importance of this study lies in that it invistigates the semantic behaviour of some verbs in English language what contributes to understanding the general semantic system of the language, and this is the main tast of linguists. The study recommended that further investigation should be made in the area of presupposition and factive verbs in order to pinpoint the sources of difficulty for learners. The results of those investigations can be used to improve EFL learning and teaching in Jordan.
\end{abstract}

Keywords: Presupposition, entailment, factive verbs, lexical relations, semantics

\section{Introduction}

The domain of this paper is semantics. In particular, it reports on the findings of a study about the problems Jordanian EFL learners encounter in their recognition of the presupposed meaning triggered by certain factive verbs.

We know that the use of a name or definite description gives rise to a presupposition of existences, e.g.

a. The Prime Minister of Malaysia is in Dublin this week.

b. Malaysia has a Prime Minister.

Other types of presupposition are produced by particular words or constructions, which together are sometimes called presupposition triggers. Some of these triggers derive from syntactic structures. Other forms of subordinate clauses may produce presuppositions. What interests us here is that many presuppositions are produced by the presence of certain words. Many of these lexical triggers are verbs, e.g. factive verbs.

\section{A review of related literature}

Peterson, Philip (1979) defined factive verbs as those verbs which take factive clauses, where factive clauses are all and only those noun phrases which are not direct questions but which permit substitution of a corresponding indirect question (Wh-nominalisation) preserving grammaticality. By looking at this definition of factive verbs, we see that it depends on syntactic test, but this syntactic test fails to predict some verbs that are factive but do not pass this test. E.g. "know" is non-factive by the test factive by intuition.

Karttunen (1971) solved the problem by making distinction between two types of factive verbs: factives, including regret, forget, resent, ... etc, and semi factives including realize, see, discover,....etc.

Kempson, Ruth (1975) made a clear and very useful distinction between factive and non factive verbs as:

1. Only factives can take the full range of gerundives (without tense or adverbial constraints) as object complements hence the distribution.

a. John regretted Bill's having whipped the dog so hard.

b. John resented Edward's seeing his sister every day.

c. *John thought Bill's whipped Mary.

d. *Edward assumed Alice's creating a fuss in each lecture.

e. *Sue proved Mary's being neurotic. 
2. Only non-factives allow the transformation of raising to object position:

a. *John regretted Mary to be right.

b. *Edward resented Bill to be the winner.

c. John believed Mary to be wrong.

d. John expected Bill to be the winner.

e. Sam proved Mary to be a fraud.

f. John was discovered to be a genius.

3. Only non-factives allow the rule of negative transportation:

a. John thought that Bill wasn't here.

Is equivalent to

b. John didn't think that Bill was here.

But this is not true of the pair $(c, d)$

c. John regretted that Bill was not there.

d. John didn't regret that Bill was there.

4. Only factives can be freely followed by the fact that $\mathrm{S}$ construction, which is synonymous with a simple that complement:

a. John regrets the fact that Mary came early.

b. John resents the fact that Mary came early.

c. *John thinks the fact that Mary came early.

d. *John imagined the fact that Mary came early.

5. Only non-factive verbs require that the tense of the embedded complement clause must agree with the superordinate verb:

a. At first my parents deeply regretted that $\left\{\mathrm{I}^{\prime} \mathrm{ve} / \mathrm{I}, \mathrm{d}\right\}$ decided not to have any more children .

b. My parents eventually realized that $\{$ I'm / I was $\}$ determined not to have any children.

c. At first my parents thought / believed / imagined that $\left\{{ }^{*} I\right.$ 've / I,d $\}$ decided not to have any children.

d. Last year I discovered that my daughter $\{*$ has been / had been $\}$ a heroin addict.

6. Only non-factive verbs allow adverb proposing from the I think that he'll be in York tomorrow.

a. Tomorrow I think that he'll be in York.

b. I imagined that John will give the game away tomorrow.

c. Tomorrow I imagined that John will give the game away.

d. I suggested we go to York town tomorrow.

e. Tomorrow I suggested we go to York town.

f. I've just discovered we'll be on holiday next week.

g. Next week I've just discovered we'll be on holiday.

h. It happens to be John's birthday tomorrow.

i. Tomorrow it happens to be John's birthday.

j. I regret that Mary is leaving tomorrow.

k. *Tomorrow I regret that Mary is leaving.

1. I resent that Mary is leaving tomorrow.

m. *Tomorrow I resent that Mary is leaving.

n. I am surprised that Mary is having tomorrow.

o. Tomorrow I am surprised that Mary is having.

Now we'll turn to the second part, which is presupposition. Gazdar, Gerald (1979) identified presupposition as potential presupposition. Sets of then are assigned to sentences in a completely mechanical way. They are what the presupposition would be if there was no projection problem, no "ambiguity" in negative sentences and no context sensitivity. A compound sentence has all pre-suppositions of its components but may not, of course, presuppose all its pre-suppositions. Even if a given sentences can never, on any occasion of use, actually presuppose all of its pre suppositions, this fact in no sense makes the assignment of that pre-supposition to the sentence incorrect: presuppositions are entities whose only role is a technical one in the process of assigning actual presuppositions to utterances. 
Stnaker(1972) and Keenan (1971) identified it as follows:

a) Sentence A pragmatically presuppose a proposition if, whenever A is uttered sincerely, the speaker of A assumes B and assumes that his audience assumes B also.

Stanlnaker (1973) offers a speaker - based definition of the notion that would require extension to include the sentence uttered, if it were to be strictly comparable with A

b) A speaker pragmatically presupposes that $\mathrm{B}$ at a given moment in a conversation just in case he is disposed to act, in his linguistic behavior, as if he takes the truth of B forgranted, and as if he assumes that his audience recognizes that he is doing so.

Stalnker (1974) developed this definition to be:

c) A proposition B is a pragmatic presupposition of a speaker in given context just in case the speaker assumes or believes that B , assumes or believes that his audience assumes or believes that B, and assumes or believes that his audiences recognizes that he is making these assumptions or has these beliefs.

He then goes on to define three alternative relations between sentences or statements and their pragmatic presuppositions.

a) Sentence A pragmatically presupposes that B just in case the use of A to make a statement is appropriate (or perhaps normal) only in context where B is presupposed by the speaker.

b) The statement that A (made in a given context) pragmatically presupposed that B just in case one can reasonably infer that the speaker is presupposing that B from that fact the statement was made.

c) The statement that A (made in a given context) pragmatically presupposes that B just in case it is necessary to assume that the speaker is presupposing that B in order to understand or correctly interpret the statement.

Thomasor (1973) defined pragmatic presupposition as

Sentence A pragmatically presupposes a proposition $\mathrm{B}$ relative to a context $\mathrm{C}$ if $\mathrm{A}$ conversationally implicates $\mathrm{B}$ relative to $\mathrm{C}$ and $\mathrm{A}$ conversationally implicates $\mathrm{B}$ relative to $\mathrm{C}$.

Karttunen (1973) defined pragmatic presupposition as follows

A pragmatically presupposes $\mathrm{B}$ relative to a set of assumed facts $\mathrm{C}$ if it is not acceptable to utter $\mathrm{A}$ in the context of $\mathrm{C}$ unless $\mathrm{C}$ entails B.

This definition reappears in a slightly different guise in Carttunen (1974)

Surface sentence A pragmatically presupposes a logical form B, if it is the case that A can be felicitously uttered only in contexts which entails B

This is modified again when it appears in Karttunen and Peters (1975)

Sentence A pragmatically presupposes proposition B if it is felicitous to utter A in order to increment a common ground $\mathrm{C}$ only incase $\mathrm{B}$ is already entailed by $\mathrm{C}$.

By looking through these definitions one can observe that they have much in common. Thus Stalnaker (1972) used "sincerity" and "assumption". Stalnker(1973) used "disposition" and "recognition". Stalnker in A (1974) used "appropriaey", Stalnker in B used "reasonable inference" and Thomson (1973), Karttunen (1973) and Karttuen Peters (1975) involved the notion of "acceptability "or "felicity".

Saeed, John (1987) argued that to presuppose something means to assume it and the narrow technical use of it in semantics is related to this. E.g.

a) He stopped turning in to a werewolf every full moon.

b) He used to turn into a werewolf every full moon.

c) I don't regret leaving London.

d) I left London.

Looking at this definition we can set up truth table for presupposition as follows:

Steep 1: If $\mathrm{P}$ (the presupposing sentence) is true then $\mathrm{q}$ (the presupposed sentence) is true.

Steep 2: If $\mathrm{P}$ is false, then $\mathrm{q}$ is still true.

Steep 3: if $q$ is true, $p$ could be either true or false.

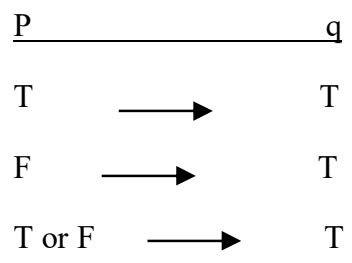


The importance of this definition is that it allows us to capture the difference between entailment and presupposition .if we negate entailing sentences, then the entailment falls, but negating presupposing sentences allows the presupposition to survive. E.g. If we have this entailment pair

I saw my father today

I saw a man today

But entailment falls by negating them .

I didn't see my father today.

I saw someone today.

By comparing the previous pair with these presupposing pairs.

The owner of the car is a man

There is an owner of the car.

Negating them does not affect presupposition

The owner of the car isn't a man.

There is an owner of the car.

The last point that we are going to mention here in this introduction is that introducing differences in verbs as factive verbs and non-factive verbs may affect presupposition so that grammarians and others might question whither facts are refereed to in

a) John realized that Mary refused the offer. And in

b) John didn't watch that Mary refused the offer.

c) Mary refused the offer.

In deed, there is a difference between the presupposition in factive cases and the presupposition in definite description cases. The latter is referred to as Referential Presupposition and the former is another sort - Factive Presupposition. So just A presupposes $\mathrm{C}$ but does not entail it.

\section{Objectives}

This paper hypothesizes that the problems in the presupposed meaning that the Jordanian EFL learners encounter because of the presence of factive verbs are the result of low proficiency level in the target language (English). Hence advanced Jordanian EFL students will not encounter such problems as low proficient ones. It also hypothesizes that both groups will find certain factive verbs more problematic than others .

Specifically this paper aims at providing answers to the following questions:

1) Finding out whether there is a relationship between proficiency level in English and the right recognition of the presupposed meaning triggered by factive verbs.

2) Identifying which factive verbs are much more problematic than others in terms of the presupposed meaning.

\section{Interaction between presupposition and factive verbs}

Kiparsky and kiparsky (1970) conducted a study investigating the interaction between presupposition and implicative triggered by factive verbs. He was mainly concerned with cognitive factives, which is the classes of factive verbs used primary to convey information about what information the subjects has or how the information is occurred or lost. Kiparsky's factives includes "know, realize, discover, notice, recognize, find out, remember, forget, be aware that, be unaware that, admit, and intuit". And a subclass of sensory factives "sense, see, smile, hear, detect, observe" .The other major class of factive verbs is the emotives factive verbs used primarily to convey the subjects of emotional attitude towards information. This class includes "regret, be annoyed, be amused, be upset, be glad, be happy, be ecstatic".

Stainaker (1974) looked at data involving factive verbs imbedded in hypothetical and question contexts. An occurrence of a factive verb, a presupposition trigger provides us with evidence that the presuppositional complement at the verb is being presupposed. Here are some examples

a) Did you regret that you had not told the truth?

b) Did you realize that you had not told the truth?

c) Did you discover that you had not told the truth?

d) Did she regret that you had not told the truth?

e) Did she realize that you had not told the truth?

f) Did she discover that you had not told the truth?

g) If I regret that I haven't told the truth, I will confess it now.

h) If I realize that I haven't told the truth, I will confess it now.

i) If I discover that I haven't told the truth, I will confess it now.

j) If she regrets that I haven't told the truth, I will confess it now. 
k) If she realizes that I haven't told the truth, I will confess it now.

1) If she discovers that I haven't told the truth, I will confess it now.

Here if we look at the examples we will see that the factive verbs are regret, realize, and discover. So the issue is whether the complement "I have not told the truth" is presupposed in each example. According to Stalnaker examples $(\mathrm{a}, \mathrm{b})$ and $(\mathrm{g})$ carry this presupposition. While (c) and $(\mathrm{h}, \mathrm{i})$ do not. According to Stalnaker, third person uses of the factive verbs , as in all the remaining examples $(\mathrm{d}, \mathrm{e}, \mathrm{f})$ and $(\mathrm{j}, \mathrm{k}, \mathrm{l})$ should be expected to carry the factive presupposition in (h). abbreviating "I have not told the truth" as Ø. Stalnaker argues that since the hypothesis that the speaker will realize $\varnothing$ is open. And the speaker has indicated this by use of the conditional, the speaker can't already believe $\varnothing$. So although the use of factive verb leads to a presumption that $\varnothing$ is being presupposed; In this case there can be no presupposition, similarly for (i). However, when the trigger is "regret" as in (g) the argument does not go through: the fact that it is open whether the speaker will regret $\varnothing$ does not let us that the speaker does not already believe $\varnothing$, so that the presupposition goes through. ; Likewise for all of the third person cases in (j,k,l). It can be open what attitude "she" will have towards $\varnothing$ in the future although the speaker and hearer already believe $\emptyset$. so the presupposition survives.

Gazdar (1979) presented a formal theory in which quantity and other implicatures cancel presupposition. Gazdar proposes that a hearer starts with an information state consisting of a set of preposition which have been established, then adds the ordinary semantic content of a new utterance, then adds any potential implicatures which are consistent with this set (and each other), and then adds any potential proposition which are consistent with that set (and each other). The presuppositions of an utterance are just those potential presupposition whish survive this vetting procedure. In our examples in (3), the potential implicature that the speaker does not know whether her or she will realize $\varnothing$ is added to the Information State before the potential preposition triggered by "realize". Gazdar's presuppositions are epistemic, and in this case the potential presupposition is that the speaker knows $\varnothing$. Assuming some further axioms that enforce monotonic growth of information, the potential presupposition is not compatible with the implecature, so the potential presupposition never gets added . In Gazdar's terms, it is canceled.

Levinson, Stephen (1983) discussed how presupposition of lower clauses sometimes fails to be inherited by the whole complex sentence. In other words, how presuppositions are sometimes defeasible by virtue of intra-sentential. He pointed that the most straight ward way in which such disappearances occur is where the presupposition of a sentence are overtly denied in a co-ordinate sentence, as for example in:

m) John doesn't regret doing a useless $\mathrm{Ph} . \mathrm{D}$. in linguistics because In fact he never did do one.

n) John didn't manage to pass his exams, in fact he didn't even try.

Obviously, one can't do this with entailments on pair of direct contradiction:

o) * John doesn't regret doing a useless $\mathrm{Ph} . \mathrm{D}$. because in fact he does regret doing a useless $\mathrm{Ph} . \mathrm{D}$.

The possibility of denying ones own presupposition is a fundamentally important property of presuppositional behavior, which forces semantic theories of presupposition into special claims about the ambiguity of negation in ways that I shall describe bellow.

In connection with overt denials as in $\mathrm{M}$ and $\mathrm{N}$, it is important to note that at least in many cases they are not possible with positive sentences. Thus the following sentences seem in contrast quite unacceptable:

p) * John regrets doing Ph.D. because in fact he never did so one.

q) * Florence has stopped beating her husband and in fact she never did beat him .

r) * It was Luke who would betray him, because in fact no one would.

A simple but important explanation of this is to claim that, at least in these cases, the affirmative sentences entail what we have called the presupposition of each of them. Thus $\mathrm{O}-\mathrm{Q}$ are simply contradictions and thus semantically anomalous. This claim leaves it open whether in addition to being entailed the alleged presupposition are also (redundantly) presupposed in the affirmative sentences, although most presuppositional theories would claim that they are . The asymmetries that thus show up between negative and positive sentences with respect to overt denial of presuppositions argue strongly for the entailment analysis in positive sentences.

We come now to the most troublesome aspect of the interaction between presupposition and factive verbs that is the projection problem, namely the behavior of presupposition in complex sentences formed by using the connectives and, or, if.... Then and the related expressions that include but, alternatively, suppose that and many others .As we notice, presupposition tend to survive in disjunctions and conditionals where entailments do not, and one might therefore be tempted to claim that these constructions are hales that just let presupposition through. That this is not the case is shown by examples like $\mathrm{S}$ and $\mathrm{T}$ :

s) If John does linguistics, he will regret it

t) John will do linguistics.

Here the consequent (the second clause of the conditional)alone would presuppose $\mathrm{T}$, but the whole conditional doesn't - clearly because the presupposition is mentioned in the first clause and is thus made hypothetical. Thus turns out to be completely general now lets consider:

u) Either John will not in the end do linguistics, or he will regret doing it . 
Here again the second clause alone presupposes T, but the whole does not. The presupposition seems to be cancelled in this case because the alternative expressed in the first clause is the negation of the presupposition of the second clause. As I said earlier this is general phenomenon.

\section{Methodology}

\subsection{Population}

The Study has two populations, namely 1) thirty BA students and 2) twenty-five MA students. The students are native speakers of Arabic majoring in English at the Department of English Language and Literature at the University of Jordan. The majority of both populations are females $(90 \%)$. Both groups went through the same selection procedures when they first applied to specialize in English Language. The MA students reflected a more advanced level in English Language when compared with. The Intermediate Group (henceforth IG) sample consisted of thirty students who were selected from a total of forty after excluding ten distorted and incomplete papers. The Advanced Group (henceforth AG) sample comprised twenty-five students who were selected from a total of thirty after excluding five distorted and incomplete papers.

The two groups were given the same tasks by the researcher during the first semester of the academic year 2004/2005.

\subsection{Data collection}

The data were elicited through a written task comprised of seven tasks that have been prepared .The seven tasks required the subjects to circle the best choice $a, b$, or $c$ that presupposes a given sentences.

The first task tests students' recognition of presupposition triggered by the factive verb regret. The second dealt with the fictive verb discover. Realize was the third. Forget, know, be aware of, and believe were the forth, fifth, sixth and seventh respectively. In each task we have the presupposed sentence, three sentences with fictive, semi- factive and non-factive verbs were presented under it. Subjects were required to circle the best choice that presupposes the previously mentioned sentences. The right choices were a, c, b, a, c, a, and d respectively.

\section{Findings and discussion}

Before proceeding with the analysis, it is useful to remind ourselves of the questions of the paper (section 3) which require an answer that specifies whether there is a relation ship between subjects proficiency level in English and their right recognition of the presupposed meaning triggered by factive verbs. And to identify which factive verbs are much more problematic than others in terms of the presupposed meaning.

In this section we will present the findings obtained from the administration of the factive verbs written task. As shone in section 4, the written task consisted of seven tasks, which tests subjects' ability to circle the best choice that presupposes the previously mentioned sentence. Choices have factive, semi-factive, and non- factive verbs.

Table (6.1) below presents a summary of the incorrect responses of each factive verb by the two groups of the study.

Table 6.1 A Summary of the Incorrect Responses of each

\begin{tabular}{llll}
\multicolumn{4}{l}{ Factive } \\
\hline No & Verb by the Two Groups of the Study \\
\hline $\mathbf{1}$ & Regret & AG & IG \\
$\mathbf{2}$ & Discover & 4 & 15 \\
$\mathbf{3}$ & Realize & 8 & 16 \\
$\mathbf{4}$ & Forget & 17 & 18 \\
$\mathbf{5}$ & Know & 10 & 17 \\
$\mathbf{6}$ & Be aware of & 13 & 22 \\
$\mathbf{7}$ & Believe & 7 & 12 \\
\hline
\end{tabular}

Table (6.1) above shows a remarkable difference in the number of incorrect responses assigned to each factive verb within and across the study. It seems that each group found some factive verbs easier or more difficult than others. Moreover, the AG seems to have outperformed the IG .In other words, the target factive verbs were not equally easy / difficult and the performance of each study group was significantly different from the others.

Moreover, there is a significantly interaction between the target factive verbs and the group level i.e. The ease / difficulty of the target factive verbs correlates positively with proficiency level of the learner.

Obviously, the AG outperformed the IG on the factive verbs test. The total number of incorrect responses is 119 for the IG and 61 for the AG. In fact this finding supports the hypotheses of the study .In order to show whether there is a significant difference between the two groups in relation to each factive verb, a number of paired comparisons were made. Table 6.2 below supports the hypotheses of the study. 
Table 6.2 Paired Comparisons for Incorrect Responses

in terms of the Target Factive Verbs Across Groups.

\begin{tabular}{lllll}
\hline No & Verb & AG & IG & sig. \\
\hline $\mathbf{1}$ & Regret & $\% 0.0$ & $\% .5$ & $* \% .5$ \\
$\mathbf{2}$ & Discover & $\% .1$ & $\% .6$ & $* \% .5$ \\
$\mathbf{3}$ & Realize & $\% .3$ & $\% .5$ & $* \% .2$ \\
$\mathbf{4}$ & Forget & $\% .6$ & $\% .5$ & $\% .-1$ \\
$\mathbf{5}$ & Know & $\% .4$ & $\% .5$ & $* \% .1$ \\
$\mathbf{6}$ & Be aware of & $\% .5$ & $\% .7$ & $* \% .2$ \\
$\mathbf{7}$ & Believe & $\% .2$ & $\% .4$ & $* \% .2$ \\
\hline \multicolumn{5}{l}{ Significant $\alpha \geq 0.01$} \\
ns =not significant
\end{tabular}

Table 6.2 makes it clear that the scores of the IG and the AG were significantly different on most of the target factive verbs. This proves beyond my doubt that proficiency level has indeed a vital effect on the number of errors committed by the learners. The judgment, of course, is in favor of the AG who scored higher on most of the target factive verbs. This comparison highly supports the hypotheses of the study.

A quick look at the table 6.2 shows that the two factive verbs (forget and be aware of) were the most problematic ones for the AG. The numbers of errors committed by the AG in terms of presupposition triggered by them is 17 and 13 errors respectively (\% 6 and \% 5) while the most problematic ones for the IG are be aware of (22 errors, \% 7) and discover (19 errors, \% 6).

Ordering verbs according to the degree of difficulty the AG encountered in presupposition triggered by them provides us with the following table.

Table 6.3 Factive Verbs Ordered according to the Degree of difficulty the AG Encountered In Presupposition Triggered by them

\begin{tabular}{llll}
\hline No & Verb & No of errors & $\%$ \\
\hline $\mathbf{1}$ & Forget & 17 & $\% .6$ \\
$\mathbf{2}$ & Be aware of & 13 & $\% .5$ \\
$\mathbf{3}$ & Know & 10 & $\% .4$ \\
$\mathbf{4}$ & Realize & 8 & $\% .3$ \\
$\mathbf{5}$ & Believe & 7 & $\% .2$ \\
$\mathbf{6}$ & Discover & 4 & $\% .1$ \\
$\mathbf{7}$ & Regret & 2 & $\% 0.0$ \\
\hline
\end{tabular}

But the order of factive verbs according to the degree of difficulty the IG encountered in presupposition triggered by them is like the following table.

Table 6.4 Factive Verbs Ordered according to the Degree of difficulty the IG Encountered In Presupposition Triggered by them

\begin{tabular}{llll}
\hline No & Verb & No of errors & \% \\
\hline $\mathbf{1}$ & Be aware of & 22 & $\% .7$ \\
$\mathbf{2}$ & Discover & 19 & $\% .6$ \\
$\mathbf{3}$ & Forget & 18 & $\% .5$ \\
$\mathbf{4}$ & Know & 17 & $\% .5$ \\
$\mathbf{5}$ & Realize & 16 & $\% .5$ \\
$\mathbf{6}$ & Regret & 15 & $\% .5$ \\
$\mathbf{7}$ & Believe & 12 & $\% .4$ \\
\hline
\end{tabular}

Table 6.3 and 6.4 show that the two groups found the factive verb be aware of the most difficult one followed by forget. 
7. Conclusions and Recommendations

\subsection{Conclusions}

The study set out to investigate whether the proficiency level of EFL learners in English affect their recognition of the presupposed meaning triggered by certain factive verbs and to identify which factive verbs are much more problematic than others in terms of the presupposed meaning.

The hypotheses stated at the beginning of the study proposed that the Advanced Group would perform better than the Intermediate Group in the factive verbs test.

The analysis of the data obtained from the administration of factive verbs test (see section 4and appendix 1) confirmed the hypotheses of the study. The two proficiency groups showed completely unequal levels of competence in responding to the items of the test. The current study came up with the following conclusions:

1) The Advanced Group did not encounter as many problems as the Intermediate Group in their recognition of presupposed meaning triggered by certain factive verbs.

2) The factive verb be aware of was the most difficult one followed by forget for the two groups.

\subsection{Recommendations for Further Researches}

The tentative findings of this study may encourage researchers to further investigate the problems that Jordanian EFL learners encounter in presupposition triggered by certain factive verbs. This can be done by conducting studies on similar groups and from different levels. The results of those investigations can be used to improve EFL learning and teaching in Jordan.

It would also be interesting to select another groups of factive verbs and to study the problems that they reflect in presupposition. Such a procedure can provide further insights about the problems of these factive verbs and whether it actually decreases by time.

The study investigated the problems that Jordanian EFL learners encounter in presupposition triggered by certain factive verbs in written discourse of two proficiency levels (i.e. Intermediate Group and Advanced Group). Other studies can be extended to investigate the oral performance of other two groups in order to capture performance on both written and spoken discourses.

\section{Sponsoring information}

The Research Council and Al Buraimi University College, the Sultanate of Oman.

\section{References}

Fillmore, C., and Langendoen, D. (1971). Studies in linguistic semantics .Holt, Rinehare and Winston, Inc: United States of America.

Gazdar, G.(1979). Pragmatics implicature, presupposition and logical forms. Academic Press: United States of America.

Kempson, R.(1975). Presuposition and the delimitation of semantics. Cambridge University Press: London.

Kyu, C., and Dinneen, D. (eds) (1979). Syntax and semantics. Volume11 presupposition. Academic Press: United States of America.

Levinson, S. (1983). Pragmatics. Cambridge University Press: London.

Rogers, A. B., Wall, D., and Murphy, J.(eds). (1977). Proceedings of the Texas conference on performatives, Presupposition, and implicatures. Center of applied linguistics: United States of America.

\section{APPENDIX 1}

\section{Factive Verbs Test}

Specialization..........................................year........

Q-Circle the best choice (a, b, or c) which presupposes (assume) the meaning of the sentence written in bold.

1. I left London.

(a) I regret leaving London.

(b) I thought that I had left London.

(c) I imagined that I had left London. 
2. Her name is Mary.
(a) I expected that her name is Mary.
(b) I thought that her name is Mary.
(c) I discovered that her name is Mary.
3. Bill was not here.
(a) I claimed that Bill was not here.
(b) I realized that Bill was not here.
(c) I supposed that Bill was not here.

4. I paid the hotel bill.

(a) I forgot that I had paid the hotel bill.

(b) I thought that I had paid the hotel bill.

(c) I forgot to pay the hotel bill.

5. Mary beat her husband.

(a) John claimed that Mary beat her husband.

(b) John wished that Mary beat her husband.

(c) John knew that Mary beat her husband.

6. Dracula was here.

(a) I was not aware that Dracula was here.

(b) I imagined that Dracula was here.

(c) I pretended that Dracula was here.

7. John was in debt.

(a) I thought that John was in debt.

(b) I believed that John was in debt.

(c) I feared that John was in debt. 